\title{
OPTIMIZING CONFIGURATION AND Procurement Processes For INDIVIDUAL PARTS
}

\author{
TEICH, T. \& OESTREICH, E.
}

Abstract: The processes for the procurement of individual components are coined by a high grade of complexity. In marked contrast to standard parts that can be identified easily through the use of unique item numbers, individual parts coming up to meet exactly the customer needs can only be identified through an additional detailed description. It is for this reason necessary that a company that offers individual components is in the position to control the procurement processes in an effective way. This paper presents a basic approach that supports the configuration and procurement processes of individual parts and components well. Basis therefore is a flexible configuration model based on generic document structures. It is for this reason possible to describe an individual part in the minutest details. Finally the created descriptions can be used to optimize the procurement processes.

Key words: product configuration, Mass Customization, Procurement, supplier networks, individualization, automotive industry
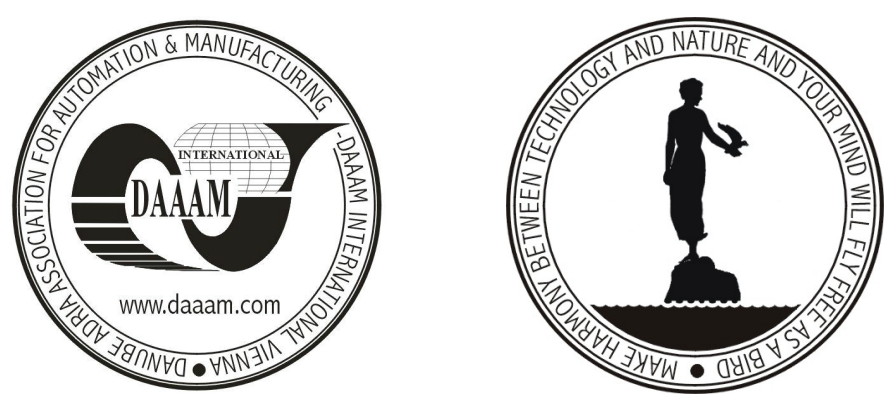

Authors' data: Prof. Dr. Teich T.[obias], Dipl. Wirtschaftsinformatiker Oestreich E.[rik], University of Applied Sciences Zwickau, Germany, tobias.teich@fhzwickau.de

This Publication has to be referred as: Teich, T. \& Oestreich, E. (2006). Optimizing Configuration and Procurement Processes for Individual Parts, Chapter 49 in DAAAM International Scientific Book 2006, B. Katalinic (Ed.), Published by DAAAM International, ISBN 3-901509-47-X, ISSN 1726-9687, Vienna, Austria DOI: $10.2507 /$ daaam.scibook.2006.49 